\title{
Long-term survival of women with basal-like ductal carcinoma in situ of the breast: a population-based cohort study
}

\author{
Wenjing Zhou ${ }^{1 *}$, Karin Jirström² ${ }^{2}$ Christine Johansson ${ }^{3}$, Rose-Marie Amini ${ }^{3}$, Carl Blomqvist ${ }^{4}$, \\ Olorunsola Agbaje ${ }^{5}$, Fredrik Wärnberg ${ }^{1}$
}

\begin{abstract}
Background: Microarray gene-profiling of invasive breast cancer has identified different subtypes including luminal A, luminal B, HER2-overexpressing and basal-like groups. Basal-like invasive breast cancer is associated with a worse prognosis. However, the prognosis of basal-like ductal carcinoma in situ (DCIS) is still unknown. Our aim was to study the prognosis of basal-like DCIS in a large population-based cohort.

Methods: All 458 women with a primary DCIS diagnosed between 1986 and 2004, in Uppland and Västmanland, Sweden were included. TMA blocks were constructed. To classify the DCIS tumors, we used immunohistochemical (IHC) markers (estrogen-, progesterone-, HER2, cytokeratin 5/6 and epidermal growth factor receptor) as a surrogate for the gene expression profiling. The association with prognosis was examined for basal-like DCIS and other subtypes using Kaplan-Meier survival analyses and Cox proportional hazards regression models.

Results: IHC data were complete for 392 women. Thirty-two were basal-like (8.2\%), 351 were luminal or HER2positive (89.5\%) and 9 unclassified (2.3\%). Seventy-six women had a local recurrence of which 34 were invasive. Another 3 women had general metastases as first event. Basal-like DCIS showed a higher risk of local recurrence and invasive recurrence 1.8 (Confidence interval (Cl) 95\%, 0.8-4.2) and 1.9 (0.7-5.1), respectively. However, the difference was not statistically significant. Also, no statistically significant increased risk was seen for triple-negative or high grade DCIS.

Conclusions: Basal-like DCIS showed about a doubled, however not statistically significant risk for local recurrence and developing invasive cancer compared with the other molecular subtypes. Molecular subtyping was a better prognostic parameter than histopathological grade.
\end{abstract}

\section{Background}

Increased use of screening mammography, beginning in the early $1980 \mathrm{~s}$, has resulted in a dramatic increase in detection of ductal carcinoma in situ (DCIS). DCIS is a pre-invasive disease with a clinically and molecularly heterogeneous presentation that poses a major challenge in both diagnosis and treatment [1-3]. A clinically accepted classification system predicting prognosis is still missing.

\footnotetext{
* Correspondence: wenjing.zhou@surgsci.uu.se

'Department of Surgical Science, Uppsala University, Uppsala, SE-75105, Sweden

Full list of author information is available at the end of the article
}

Recently, the idea of using molecular subtyping to predict the prognosis of invasive breast cancer has been widely accepted [4-8]. The introduction of highthroughput DNA microarray technologies marked an entirely new era of genome-wide approaches to predict prognosis and outcome $[9,10]$. According to similarities in gene expression characteristics, Perou et al., [11] creatively classified breast cancer into five subtypes: luminal A, luminal B, basal like, HER2-positive and normal-like. Molecular subtypes have been shown to have prognostic and treatment predictive value. Among those, the basallike tumors are characterized as expressing genes related to myoepithelial cells [12]. Follow-up studies have shown that basal-like cancer is associated with a higher
C Biomed Central 
risk of disease recurrence, distant metastasis and shorter survival. The poorer outcome of patients with basal-like tumors has been shown in different patient populations [13-17]. However, the prognosis of basal-like DCIS still unknown.

In this study, our aim was to investigate the prognosis of basal-like DCIS compared to other subtypes in a large population-based cohort. To classify the DCIS tumors, we used immunohistochemical (IHC) markers that have previously been used as a surrogate marker for the gene expression profiles [16-21]. Livasy et al., have earlier shown that IHC can be used for the identification of basal like DCIS [18]. We identified the subtypes of DCIS in tumors from a cohort of 458 women with tumor material assembled in tissue micro arrays (TMA) [22]. To our knowledge, this study is the first to examine the prognosis of DCIS in relation to different molecular subtypes defined by IHC.

\section{Methods}

\section{Patients}

We recruited all 458 women who were diagnosed with a primary DCIS between 1986 and 2004 in Uppland and Västmanland, Sweden.

\section{TMA construction}

H\&E sections from all eligible cases were reviewed to select the area from which the cores for the TMAs would be taken. Prior to the TMA construction, all primary DCIS cases were histopathologically re-evaluated by one pathologist (KJ). Two cores of $1.0 \mathrm{~mm}$ in diameter were mounted into the recipient TMA blocks using a manual arraying device (MTA-1, Beecher Inc, WI, USA). The concordance of IHC staining between original whole section slides and TMA-slides and between biopsies from the same lesion in DCIS has earlier been evaluated in a subset of the cohort [23,24]. In total, ten TMA blocks were constructed from 458 cancer samples.

\section{IHC and silver-enhanced in situ hybridization (SISH)}

We performed IHC for estrogen receptor (ER), progesterone receptor (PR), human epidermal growth factor receptor 2 (HER2), cytokeratin 5/6 (CK5/6) and epidermal growth factor receptor (EGFR) on $4 \mu \mathrm{m}$ paraffin sections cut from the TMAs. Immunostains for each marker were performed on a Dako Autostainer (Dako Corporation). IHC was conducted according to established protocols. Appropriate positive and negative controls were included in all staining runs.

HER2 SISH was performed on an automated instrument, Ventana Benchmark (Ventana Medical Systems, Tucson, AZ), as per the manufacturer's protocols for the INFORM HER2 DNA probe and chromosome 17 probes. Testing for the HER2 gene and chromosome
17 was performed on sequential sections. Both probes are labeled with dinitrophenol. Denaturation occurred on the instrument with enzyme digestion in protease 3 for 8 minutes. The detection system used a multimer labeled with goat antirabbit antibody horseradish peroxidase as the linking step. Visualization occurred with the sequential addition of silver acetate as the source of ionic silver, hydroquinone, and hydrogen peroxide to give a black metallic silver precipitate at the probe site. Counterstaining was performed with hematoxylin II on the instrument. The time taken for the complete run is 6.5 hours. Both HER2 and chromosome 17 detection were performed on the same slide run. Gene amplification was assessed using the American Society of Clinical Oncology/College of American Pathologists guideline and Australian HER2 Advisory Board criteria for single HER2 probe testing (diploid, 1 to 2.5 copies/nucleus; polysomy $>2.5$ to 4 copies/nucleus; equivocal, $>4$ to 6 copies/nucleus; low-level amplification, $>6$ to 10 copies/ nucleus; and high-level amplification >10 copies/ nucleus) and for dual HER2/CHR17 probe testing (nonamplified ratio <1.8; equivocal ratio, 1.8 to 2.2 ; gene amplification, $>2.2$ ). The status of HER2 protein expression was assessed relying on SISH. For those cases on which SISH failed, the expression was based on IHC.

\section{Scoring and classification}

Stained TMA slides were scanned (ScanScope $\mathrm{XT}^{\odot}$, Aperio, USA) for evaluation of expression of ER, PR, HER2, CK5/6 and EGFR by ImageScope (Aperio, USA). Tumor cells that showed nuclear staining for ER or PR (> 10\% of tumor cell nuclei staining) were considered ER or PR-positive respectively. Using the HerceptTest ${ }^{\mathrm{TM}}$ classification system, tumors were considered HER2 positive if the score was $3+$. Cases were considered CK 5/6-positive or EGFR-positive if any cytoplasmic and/or membranous staining was detected in the tumor cells, even if focal. These latter IHC criteria are similar to those previously used for scoring these markers in invasive breast cancers $[18,22,25,26]$. If only one core included enough tumor tissue this was used for classification but at least 200 cells had to be present. Each tumor marker was scored by one single observer; ER, PR and HER 2 by WZ, EGFR and CK5/6 by CJ and SISH by RMA.

For this study, the IHC subtype definitions used were the refined definitions used in the analysis of invasive breast cancer: basal-like (ER-, HER2-, EGFR+ and/or cytokeratin 5/6+) [17]. Cases classified as negative for all the above markers were defined as unclassified is this study. Cases with missing data, due to lack of tumor tissue in the TMAs, were excluded from the further analyses. In the survival analyses we compared the basal-like group with all other DCIS together. 


\section{Follow-up and Study End Points}

Follow-up started on the day of diagnosis and concluded on the date the patient was last observed or the date of death. The database was frozen for the statistical analyses based on follow-up through 30th April 2008. Complete follow-up was achieved for all 458 patients.

For this study, the two primary end points were local recurrence and invasive- or general recurrence. Local recurrence was defined as any ipsilateral recurrence (in situ or invasive). In addition, we defined "invasive- or general recurrence" as occurrence of an invasive ipsilateral recurrence, general metastasis or breast cancerspecific death, whichever occurred first. All women with an invasive local recurrence were included as cases regarding both endpoints. The endpoint "invasive- or general recurrence" was constructed to find patients with a biologically more aggressive disease. Contralateral breast tumors were considered as new primary breast cancers.

\section{Statistic analyses}

Baseline characteristics among patients with different molecular subtypes were compared by Chi-square for categorical variables or analysis of variance for continuous variables. Survival and probabilities of local recurrence and invasive disease among patients with different molecular subtypes were first compared by the KaplanMeier method. Cox proportional hazards regression models were used to calculate hazard ratios (HRs) with 95\% confidence intervals (CIs), with adjustment for age in the univariate analysis and further, histological grade, type of surgery, tumor size, detection mode and postoperative radiotherapy in the multivariate analysis. Kaplan-Meier curves and Cox proportional hazard models were used to assess the association between molecular subgroup and progression of breast cancer. Data were analyzed using the SAS (SAS Institute, Cary, NC) and R softwares.

This study was approved by the Ethics Committee at Uppsala University Hospital (Dnr 2005: 118). In this retrospective cohort study we did not have to get an informed consent from the women according to the ethical approval, Dnr 170/95 and 99/422.

\section{Results}

\section{Baseline Characteristics}

Baseline characteristics according to the molecular subtype of 392 eligible study participants (66 women did not get enough IHC information) are presented in Table 1. The median follow-up was 122 months (range 3-130). Among the 392 women, 32 (8.2\%) were classified as basal-like, $351(89.5 \%)$ as luminal or HER2positive, and $9(2.3 \%)$ were unclassified. The median age at diagnose was 58 years (range 30-90 years). All basic characteristics, including age, tumor size and grade, were evenly distributed between the basal-like and non basal-like tumors. No women received antiestrogen or chemotherapy after primary surgery. Type of surgery, mastectomy vs. breast conserving surgery (BCS) and postoperative radiotherapy were decided according to local tradition. BCS in Sweden means removing a sector of the breast parenchyma in up to a quadrant of the breast, aiming for a $10 \mathrm{~mm}$ free margin. The breast parenchyma is removed from behind the areola margin to the periphery of the gland. Postoperative radiotherapy was given to 140 of 298 women undergoing BCS. It was generally given at 25 occasions, up to 50 Grey. A small part of these women were included in a Swedish study randomizing between radiotherapy or not after BCS for a primary DCIS [27]. Others were given radiotherapy based on tumor size and histopathological grade. However, at that time, no criteria for radiotherapy regarding size or grade were given in the Swedish National Guidelines.

\section{Survival Outcomes \\ 2.1 Local-recurrence}

Of the 76 women who had a local recurrence, $42 \mathrm{had}$ an in situ recurrence and 34 an invasive recurrence. Median follow-up to local recurrence was 97.5 months (range 3-255). In both the univariate and multivariate models, basal-like DCIS showed a higher risk of local recurrence compared with non basal-like DCIS, hazard ratio (HR), 1.7 (CI 95\%: 0.8-3.8) and 1.8 (0.8-4.2) respectively (Table 2). However, the difference was not statistically significant. When only looking at women who had BCS, the risk for basal-like DCIS was equally higher (Table 2). Kaplan-Meier analyses were also made for all women and those undergoing BCS separately. The analyses showed a higher risk for basal-like DCIS compared to the non basal-like group but it was not statistically significant. The p-value was 0.08 for all women and 0.26 for women undergoing BCS (Figure 1a).

\subsection{Invasive- or general recurrence}

Forty-seven women developed invasive disease. Fortyfour had an invasive local recurrence (of which 10 first had an in situ local recurrence and then an invasive local recurrence). Three women had general metastases as the first event. Eight died from breast cancer, but all of these had had a local recurrence or general metastases before death. Median follow-up to an invasive- or general recurrence was 111.5 months (range 3-255). Basal-like DCIS showed a higher risk of invasive- or general recurrence compared with non basal-like DCIS, HR, 2.0 (CI 95\%: 0.8-5.0) and 1.9 (0.7-5.1) respectively (Table 2). However, the difference was not statistically significant. When only looking at women who had BCS, the risk for basal-like DCIS was also about doubled, but the risk was not statistically significant higher (Table 2). 
Table 1 Characteristics of DCIS molecular subgroups, by immunohistochemistry in 392 women with a primary DCIS

\begin{tabular}{|c|c|c|c|}
\hline Characteristics & Basal-like $(n=32,8.2 \%)$ & Non basal-like $(n=360,91.8 \%)$ & $P$ \\
\hline Age at entry, mean $\pm S D(n=392)$ & $56.7 \pm 12.6$ & $57.8 \pm 11.5$ & 0.6 \\
\hline Tumor size, number $(\%)(n=352)$ & & & 0.84 \\
\hline$\leq 15 \mathrm{~m}$ & $16(59.3)$ & $175(53.9)$ & \\
\hline$>15 \mathrm{~mm}$ & $8(29.6)$ & $104(32.0)$ & \\
\hline Multifocal & $3(11.1)$ & $46(14.2)$ & \\
\hline Tumor grade*, number $(\%)(n=388)$ & & & 0.11 \\
\hline । & $1(3.1)$ & $29(8.2)$ & \\
\hline$\|$ & $11(34.4)$ & $171(48.0)$ & \\
\hline III & $20(62.5)$ & $156(43.8)$ & \\
\hline Detection mode, number $(\%)(n=391)$ & & & 0.3 \\
\hline Screening & $22(68.8)$ & $276(76.9)$ & \\
\hline Clinically & $10(31.3)$ & $83(23.1)$ & \\
\hline Type of surgery, number (\%) $(n=392)$ & & & 0.61 \\
\hline Breast Conserving Surgery & $26(81.3)$ & $272(75.6)$ & \\
\hline Mastectomy & $6(18.8)$ & $88(24.4)$ & \\
\hline Postoperative radiotherapy, number $(\%)(n=392)$ & & & 0.72 \\
\hline Yes & $10(31.3)$ & $130(36.1)$ & \\
\hline No & $22(68.8)$ & $230(63.9)$ & \\
\hline
\end{tabular}

* Tumor grade: DCIS were classified according to the European Organization for Research and Treatment of Cancer (EORTC) system.

Kaplan-Meier analyses also showed a non-statistically higher risk for invasive- or general recurrence for the basal-like DCIS ( $\mathrm{p}=0.15)$ as seen in Figure $1 \mathrm{~b}$ and the p-value for women undergoing BCS was 0.16.

2.3 Triple-negative group vs. non triple-negative group We also assessed the prognostic implications of triple-negative (ER-, PR- and HER2-negative) vs. non triple-negative DCIS. Of all 458 women, 409 could be classified. Thirty two were classified as triple-negative and 377 as not. Triple-negative tumors had a HR of 1.1 (95\% CI, 0.4-2.7) and 1.1 (0.4-2.9) for local recurrence compared with the non triple-negative in the univariate and multivariate analyses, respectively. The adjusted HR for an invasive- or general recurrence in the triple-negative group compared with women in non triple-negative was $1.4(0.5-4.0)$ and $1.6(0.6-4.8)$.

Kaplan-Meier analyses showed no statistically significantly higher risk for local recurrence or invasive- or general recurrence for the triple-negative DCIS, neither in the subset of women undergoing BCS ( $p=0.86$ and 0.25 respectively) nor including all women ( $\mathrm{p}=0.67$ and 0.44 respectively). (Table 2 and Figure $2 \mathrm{a}-\mathrm{b}$ ).

Of the 392 women with complete IHC data, 32 were classified as basal-like and 32 as triple-negative. However, only 24 women were classified as both basal-like and triple-negative. These subgroups were too small to do any statistical analyses on but during the follow-up, the 8 women who were basal-like and non triplenegative had four invasive- or general recurrences and the 8 women who were triple-negative and non basallike only had one invasive recurrence.

\section{Discussion}

We have conducted a population-based study of primary DCIS to assess the association between an IHC surrogate basal-like DCIS genotype and prognosis. Our results showed that basal-like DCIS had a higher risk of local recurrence and a higher risk of developing invasive cancer compared to other DCIS. The risk was almost doubled but this was not statistically significant.

In our study, we defined basal-like DCIS as those that were ER-negative, HER2-negative, but positive for either CK 5/6 or EGFR. Nielsen et al [19], who proposed these criterions in 2004 for invasive breast cancer, found that defining basal-like breast cancer in this way resulted in $76 \%$ sensitivity and $100 \%$ specificity, when the gene expression signature was used as gold standard. Abd El-Rehim et al., [28] studied over 1000 cases of invasive breast cancer with 26 IHC markers and identified 6 clusters of tumors. Five of these clusters roughly corresponded to the 5 subtypes identified earlier; the remaining group consisted of only 4 cases. Livasy et al., [18] then verified and confirmed the criteria in DCIS tumors. Today, IHC is increasingly used as a surrogate for molecular gene profiling since it allows classification of tumors at an affordable costs and in the absence of fresh tissue speciments [29]. Moreover, these four subgroups have distinguishing features closely associated with subtypes defined by gene expression profiling, including distinct clinical outcomes [30].

A possible cause of subtype misclassification is the HER2 status based on IHC scoring. We assessed the status of HER2 by SISH and used IHC only in those cases 
Table 2 Cox regression analyses by molecular subgroup, by immunohistochemistry

\begin{tabular}{|c|c|c|c|c|}
\hline & \multicolumn{2}{|c|}{ All $(n=392)$} & \multicolumn{2}{|c|}{ Breast Conserving Surgery $(n=298)$} \\
\hline & $\begin{array}{c}\text { Univariate HR } \\
(95 \% \mathrm{Cl})\end{array}$ & $\begin{array}{c}\text { Adjusted* HR } \\
(95 \% \mathrm{Cl})\end{array}$ & $\begin{array}{c}\text { Univariate HR } \\
(95 \% \mathrm{Cl})\end{array}$ & $\begin{array}{l}\text { Adjusted* HR } \\
(95 \% \mathrm{Cl})\end{array}$ \\
\hline & \multicolumn{4}{|c|}{ Event: local recurrence $(n=76)$} \\
\hline \multicolumn{5}{|l|}{ Gene-expression classification } \\
\hline Non basal-like $(n=360)$ & 1 (Reference) & 1 & 1 & 1 \\
\hline Basal-like $(n=32)$ & $1.7(0.8-3.8)$ & $1.9(0.8-4.2)$ & $1.6(0.7-3.6)$ & $1.8(0.7-4.2)$ \\
\hline \multicolumn{5}{|l|}{ Triple-negative classification } \\
\hline Non triple-negative $(n=377$ ) & 1 (Reference) & 1 & 1 & 1 \\
\hline Triple-negative $(n=32)$ & $1.1(0.4-2.7)$ & $1.1(0.4-2.9)$ & $1.0(0.4-2.7)$ & $1.0(0.3-2.9)$ \\
\hline \multicolumn{5}{|l|}{ Tumor grade } \\
\hline I $(n=30)$ & 1 (Reference) & 1 & 1 & 1 \\
\hline$\|(n=182)$ & $1.2(0.4-3.4)$ & $1.4(0.5-4.0)$ & $1.3(0.5-3.9)$ & $1.4(0.5-3.9)$ \\
\hline III (n = 176) & $1.0(0.3-2.9)$ & $1.3(0.5-3.9)$ & $1.4(0.5-4.0)$ & $1.4(0.5-4.2)$ \\
\hline \multicolumn{5}{|l|}{ Postoperation radiotherapy } \\
\hline No $(n=252)$ & 1 (Reference) & 1 & 1 & 1 \\
\hline \multirow[t]{2}{*}{ Yes $(n=140)$} & $0.9(0.5-1.5)$ & $0.7(0.4-1.3)$ & $0.8(0.4-1.4)$ & $0.7(0.4-1.4)$ \\
\hline & \multicolumn{4}{|c|}{ Event: invasive- and general recurrence $(n=47)$} \\
\hline \multicolumn{5}{|l|}{ Gene-expression classification } \\
\hline Non basal-like $(n=360)$ & 1 (Reference) & 1 & 1 & 1 \\
\hline Basal-like $(n=32)$ & $2.0(0.8-5.0)$ & $1.9(0.7-5.1)$ & $2.2(0.8-5.6)$ & $2.3(0.8-6.1)$ \\
\hline \multicolumn{5}{|l|}{ Triple-negative classification } \\
\hline Non triple-negative $(n=377)$ & 1 (Reference) & 1 & 1 & 1 \\
\hline Triple-negative $(n=32)$ & $1.4(0.5-4.0)$ & $1.6(0.6-4.8)$ & $1.7(0.6-4.9)$ & $2.1(0.7-6.3)$ \\
\hline \multicolumn{5}{|l|}{ Tumor grade } \\
\hline I $(n=30)$ & 1 (Reference) & 1 & 1 & 1 \\
\hline$\|(\mathrm{n}=182)$ & $1.0(0.3-3.3)$ & $1.1(0.3-3.8)$ & $1.1(0.3-3.8)$ & $1.1(0.3-3.8)$ \\
\hline III (n = 176) & $0.7(0.2-2.4)$ & $1.1(0.3-3.9)$ & $0.9(0.2-3.1)$ & $1.0(0.3-3.9)$ \\
\hline \multicolumn{5}{|l|}{ Postoperation radiotherapy } \\
\hline No $(n=252)$ & 1 (Reference) & 1 & 1 & 1 \\
\hline Yes $(n=140)$ & $0.8(0.4-1.6)$ & $0.7(0.3-1.5)$ & $0.7(0.3-1.4)$ & $0.7(0.3-1.6)$ \\
\hline
\end{tabular}

where SISH failed. SISH results are more reliable [31,32] especially for the borderline cases scored as $2+$ by IHC. By using both methods we should have minimized the risk of subtype misclassification.

Our results indicated that the molecular subtypes of DCIS were not related to basic characteristics as histopathological grade and tumor size. However, many potential prognostic factors may interact with the choice of adjuvant therapy [29] and we therefore adjusted for adjuvant treatment and type of surgery in the analyses. In this study, no women received chemotherapy or antiestrogen. One hundred and forty received postoperative radiotherapy. The percentage of patients who received postoperative radiotherapy was fairly evenly distributed among the groups with different subtype of DCIS. The type of surgery was also evenly distributed.

Basal-like invasive breast cancer is an entity that is largely characterized by positive expression of basal CKs and other genes that are characteristic of basal-like cells and by high proliferative activity. Basal-like invasive breast cancer is considered to be associated with poor prognosis [13] and this supposition has been proved in many studies $[4,5,13,17,33,34]$. In our study, we found about a doubled risk for local recurrence and invasiveor general recurrences for basal-like DCIS. The higher risk was not statistically significant but, on the other hand, it was consistent in the univariate, multivariate and Kaplan-Meier analyses for all patients and for the subgroup of patients with BCS. Although we have conducted a population-based study with long follow-up, we were not able to show a statistically significantly poorer prognosis for the basal-like DCIS. Like in invasive breast cancer, the basal-like subgroup is small and this makes the statistical power low and a conclusive study would have to include a much larger number of patients. Today, we take nuclear grade, size, necrosis and margins into consideration when designing adjuvant treatment after BCS of DCIS according to the Swedish 
(a)

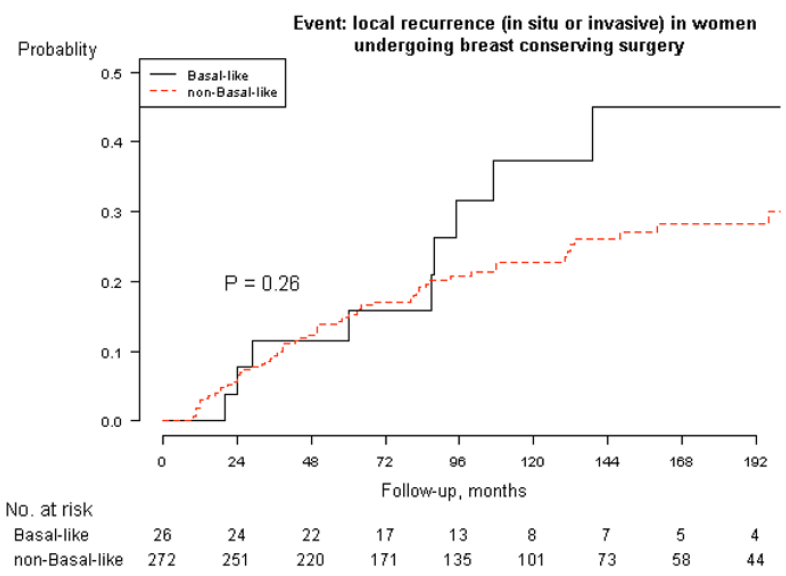

(b)

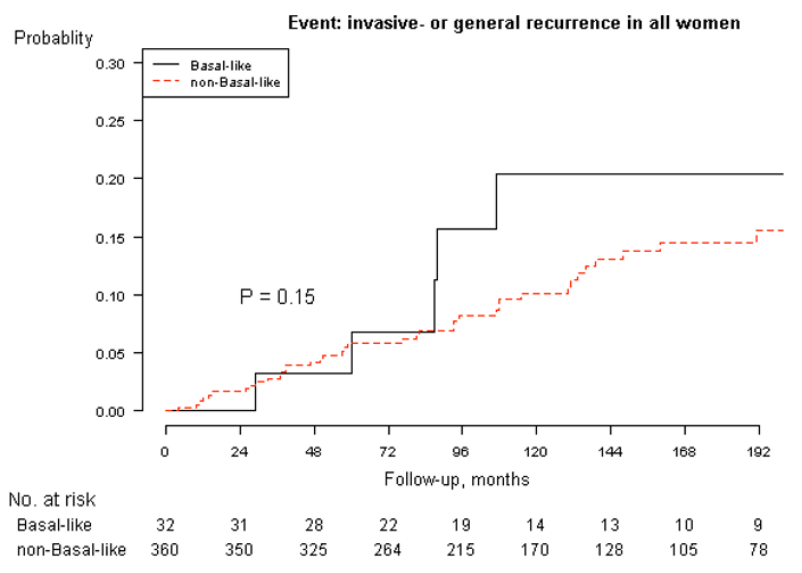

Figure 1 Kaplan-Meier analyses of local recurrence and invasive- and general recurrence by DCIS molecular subgroup by immunohistochemistry. (a) Local recurrence (in situ or invasive) in women with a primary DCIS, undergoing breast-conserving surgery (BCS), by molecular subtype. (b) Invasive- or general recurrence in all women with a primary DCIS by molecular subtype.

National Guidelines from the Swedish Breast Cancer Group [35]. In this study, grade did not relate to prognosis (see Table 2) and molecular subtyping by IHC might indeed be more useful.

We also investigated the prognosis of triple-negative DCIS. In invasive cancer, triple-negative tumors have been shown to have a worse prognosis [36-38]. We observed a slightly elevated risk for developing invasive disease, but this was not statistically significant. In some studies, triple-negative and basal-like DCIS cases have been considered to have a fairly similar prognosis.
In our study, there was a considerable miss-match between these cases as already described in invasive breast cancer by others $[21,39,40]$.

\section{Conclusions}

In conclusion, basal-like DCIS showed about a doubled, however not statistically significant risk for local recurrence and developing invasive cancer compared with the other molecular subtypes. In this study, molecular subtyping was a better prognostic parameter than histopathological grade. (a)

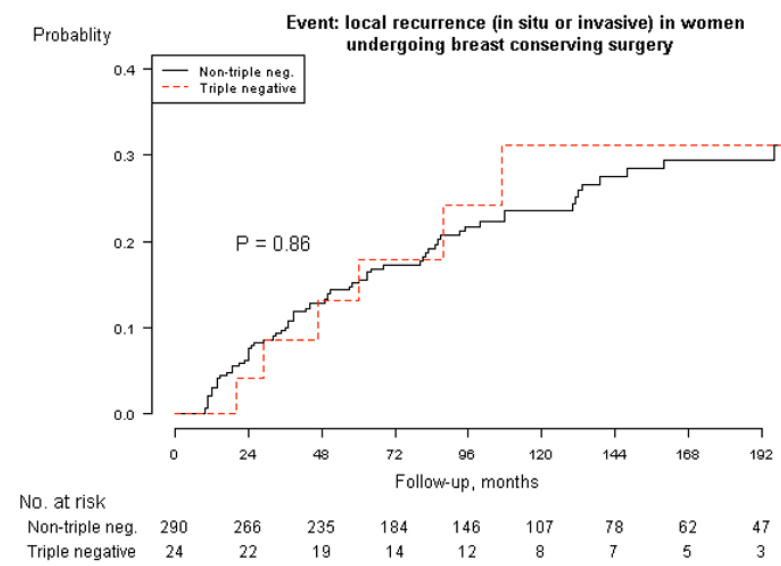

(b)

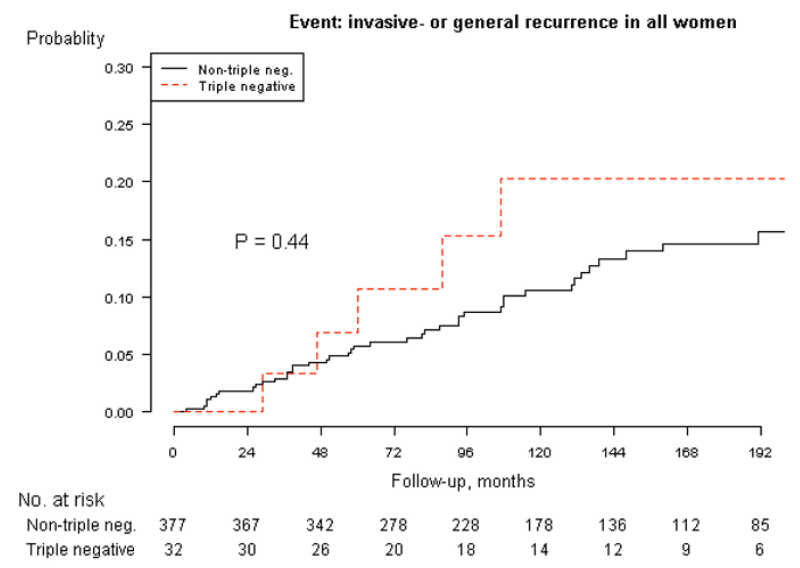

Figure 2 Kaplan-Meier analysis of local recurrence and invasive- and general recurrence by triple-negative and non triple-negative DCIS. (a) Local recurrence (BCS), triple negative DCIS vs. non-triple negative DCIS. (b) Invasive- or general recurrence in all women, triple negative DCIS vs. non-triple negative DCIS. 


\section{List of abbreviations}

DCIS: ductal carcinoma in situ; IHC: immunohistochemistry; Cl: Confidence interval; HR: hazard ratio; TMA: tissue microarrays; ER: oestrogen receptor; PR: progesterone receptor; HER2: human epidermal growth factor receptor 2; CK5/6: cytokeratin 5/6; EGFR: epidermal growth factor receptor.

\section{Acknowledgements}

This study was supported by the Swedish Cancer Society (4920-B06-03PCD to FW). We thank Hans Garmo for his initial work in the data analysis.

\section{Author details}

'Department of Surgical Science, Uppsala University, Uppsala, SE-75105, Sweden. ${ }^{2}$ Department of Laboratory Medicine, Lund University, Lund, Sweden. ${ }^{3}$ Department of Genetics and Pathology, Uppsala University, Uppsala, Sweden. ${ }^{4}$ Department of Oncology, Helsinki University Central Hospital, Finland. ${ }^{5}$ School of Medicine, Division of Cancer Studies, King's College, London, UK.

\section{Authors' contributions}

WZ was responsible for data analyses, manuscript preparation and editing. $\mathrm{KJ}$ performed $\mathrm{IHC}$ and SISH stainings from the TMAs, and helped to provide expertise in breast cancer pathology. WZ, JC and RMA were involved in pathology review, scoring of stains and contributed substantially to manuscript editing. CB helped with the interpretation of the results and with drafting the manuscript. OA helped to provide expertise in data analyses. FW designed the overall study, compiled and curated the datasets, coordinated the study and helped to draft and finalize the manuscript. All authors read and approved the final manuscript.

\section{Competing interests}

The authors declare that they have no competing interests.

Received: 17 July 2010 Accepted: 30 November 2010

Published: 30 November 2010

\section{References}

1. Turashvili G, Bouchal J, Baumforth K, Wei W, Dziechciarkova M, Ehrmann J, Klein J, Fridman E, Skarda J, Srovnal J, et al: Novel markers for differentiation of lobular and ductal invasive breast carcinomas by laser microdissection and microarray analysis. BMC cancer 2007, 7:55.

2. Tsikitis VL, Chung MA: Biology of ductal carcinoma in situ classification based on biologic potential. American journal of clinical oncology 2006, 29(3):305-310.

3. Namba R, Maglione JE, Davis RR, Baron CA, Liu S, Carmack CE, Young LJ Borowsky AD, Cardiff RD, Gregg JP: Heterogeneity of mammary lesions represent molecular differences. BMC cancer 2006, 6:275.

4. Zhao J, Liu H, Wang M, Gu L, Guo X, Gu F, Fu L: Characteristics and prognosis for molecular breast cancer subtypes in Chinese women. J Surg Oncol 2009, 100(2):89-94.

5. Spitale A, Mazzola P, Soldini D, Mazzucchelli L, Bordoni A: Breast cancer classification according to immunohistochemical markers: clinicopathologic features and short-term survival analysis in a population-based study from the South of Switzerland. Ann Oncol 2009, 20(4):628-635.

6. Nofech-Mozes S, Trudeau M, Kahn HK, Dent R, Rawlinson E, Sun P, Narod SA, Hanna WM: Patterns of recurrence in the basal and non-basal subtypes of triple-negative breast cancers. Breast Cancer Res Treat 2009.

7. Lund MJ, Trivers KF, Porter PL, Coates RJ, Leyland-Jones B, Brawley OW, Flagg EW, O'Regan RM, Gabram SG, Eley JW: Race and triple negative threats to breast cancer survival: a population-based study in Atlanta, GA. Breast Cancer Res Treat 2009, 113(2):357-370.

8. Wirapati P, Sotiriou C, Kunkel S, Farmer P, Pradervand S, Haibe-Kains B Desmedt C, Ignatiadis M, Sengstag T, Schutz F, et al: Meta-analysis of gene expression profiles in breast cancer: toward a unified understanding of breast cancer subtyping and prognosis signatures. Breast Cancer Res 2008, 10(4):R65.

9. Schena M, Shalon D, Davis RW, Brown PO: Quantitative monitoring of gene expression patterns with a complementary DNA microarray. Science 1995, 270(5235):467-470.
10. Pease AC, Solas D, Sullivan EJ, Cronin MT, Holmes CP, Fodor SP: Lightgenerated oligonucleotide arrays for rapid DNA sequence analysis. Proceedings of the National Academy of Sciences of the United States of America 1994, 91(11):5022-5026.

11. Perou CM, Sorlie T, Eisen MB, van de Rijn M, Jeffrey SS, Rees CA, Pollack JR, Ross DT, Johnsen H, Akslen LA, et al: Molecular portraits of human breast tumours. Nature 2000, 406(6797):747-752.

12. Sorlie T, Wang Y, Xiao C, Johnsen H, Naume B, Samaha RR, BorresenDale AL: Distinct molecular mechanisms underlying clinically relevant subtypes of breast cancer: gene expression analyses across three different platforms. BMC Genomics 2006, 7:127.

13. Sorlie T, Perou CM, Tibshirani R, Aas T, Geisler S, Johnsen H, Hastie T, Eisen MB, van de Rijn M, Jeffrey SS, et al: Gene expression patterns of breast carcinomas distinguish tumor subclasses with clinical implications. Proceedings of the National Academy of Sciences of the United States of America 2001, 98(19):10869-10874.

14. Sorlie T, Tibshirani R, Parker J, Hastie T, Marron JS, Nobel A, Deng S, Johnsen H, Pesich R, Geisler $\mathrm{S}$, et al: Repeated observation of breast tumor subtypes in independent gene expression data sets. Proceedings of the National Academy of Sciences of the United States of America 2003, 100(14):8418-8423.

15. Sotiriou $C$, Neo SY, MCShane LM, Korn EL, Long PM, Jazaeri $A$, Martiat $P$, Fox SB, Harris AL, Liu ET: Breast cancer classification and prognosis based on gene expression profiles from a population-based study. Proceedings of the National Academy of Sciences of the United States of America 2003, 100(18):10393-10398.

16. Potemski P, Kusinska R, Watala C, Pluciennik E, Bednarek AK, Kordek R: Prognostic relevance of basal cytokeratin expression in operable breast cancer. Oncology 2005, 69(6):478-485.

17. Carey LA, Perou CM, Livasy CA, Dressler LG, Cowan D, Conway K, Karaca G, Troester MA, Tse CK, Edmiston S, et al: Race, breast cancer subtypes, and survival in the Carolina Breast Cancer Study. JAMA 2006, 295(21):2492-2502.

18. Livasy CA, Perou CM, Karaca G, Cowan DW, Maia D, Jackson S, Tse CK, Nyante S, Millikan RC: Identification of a basal-like subtype of breast ductal carcinoma in situ. Hum Pathol 2007, 38(2):197-204.

19. Nielsen TO, Hsu FD, Jensen K, Cheang M, Karaca G, Hu Z, HernandezBoussard T, Livasy C, Cowan D, Dressler L, et al: Immunohistochemical and clinical characterization of the basal-like subtype of invasive breast carcinoma. Clin Cancer Res 2004, 10(16):5367-5374.

20. Banerjee S, Reis-Filho JS, Ashley S, Steele D, Ashworth A, Lakhani SR Smith IE: Basal-like breast carcinomas: clinical outcome and response to chemotherapy. J Clin Pathol 2006, 59(7):729-735.

21. Cheang MC, Voduc D, Bajdik C, Leung S, McKinney S, Chia SK, Perou CM, Nielsen TO: Basal-like breast cancer defined by five biomarkers has superior prognostic value than triple-negative phenotype. Clin Cancer Res 2008, 14(5):1368-1376

22. Livasy CA, Karaca G, Nanda R, Tretiakova MS, Olopade Ol, Moore DT, Perou CM: Phenotypic evaluation of the basal-like subtype of invasive breast carcinoma. Mod Pathol 2006, 19(2):264-271.

23. Warnberg F, Amini RM, Goldman M, Jirstrom K: Quality aspects of the tissue microarray technique in a population-based cohort with ductal carcinoma in situ of the breast. Histopathology 2008, 53(6):642-649.

24. Jirstrom K, Ringberg A, Ferno M, Anagnostaki L, Landberg G: Tissue microarray analyses of $\mathrm{G} 1 / \mathrm{S}$-regulatory proteins in ductal carcinoma in situ of the breast indicate that low cyclin D1 is associated with local recurrence. Br J Cancer 2003, 89(10):1920-1926.

25. Jumppanen $M$, Gruvberger-Saal S, Kauraniemi $P$, Tanner M, Bendahl PO, Lundin M, Krogh M, Kataja P, Borg A, Ferno M, et al: Basal-like phenotype is not associated with patient survival in estrogen-receptor-negative breast cancers. Breast Cancer Res 2007, 9(1):R16.

26. Ihemelandu CU, Leffall LD, Dewitty RL, Naab TJ, Mezghebe HM, Makambi KH, Adams-Campbell L, Frederick WA: Molecular breast cancer subtypes in premenopausal African-American women, tumor biologic factors and clinical outcome. Ann Surg Oncol 2007, 14(10):2994-3003.

27. Emdin SO, Granstrand B, Ringberg A, Sandelin K, Arnesson LG, Nordgren H, Anderson H, Garmo H, Holmberg L, Wallgren A: SweDCIS: Radiotherapy after sector resection for ductal carcinoma in situ of the breast. Results of a randomised trial in a population offered mammography screening. Acta Oncol 2006, 45(5):536-543. 
28. Abd El-Rehim DM, Ball G, Pinder SE, Rakha E, Paish C, Robertson JF, Macmillan D, Blamey RW, Ellis IO: High-throughput protein expression analysis using tissue microarray technology of a large well-characterised series identifies biologically distinct classes of breast cancer confirming recent CDNA expression analyses. Int J Cancer 2005, 116(3):340-350.

29. Tang P, Wang J, Bourne P: Molecular classifications of breast carcinoma with similar terminology and different definitions: are they the same? Hum Pathol 2008, 39(4):506-513.

30. Tang P, Skinner KA, Hicks DG: Molecular classification of breast carcinomas by immunohistochemical analysis: are we ready? Diagn $\mathrm{Mol}$ Pathol 2009, 18(3):125-132.

31. Francis GD, Jones MA, Beadle GF, Stein SR: Bright-field in situ hybridization for HER2 gene amplification in breast cancer using tissue microarrays: correlation between chromogenic $(\mathrm{CISH})$ and automated silver-enhanced (SISH) methods with patient outcome. Diagn Mol Pathol 2009, 18(2):88-95.

32. Shousha S, Peston D, Amo-Takyi B, Morgan M, Jasani B: Evaluation of automated silver-enhanced in situ hybridization (SISH) for detection of HER2 gene amplification in breast carcinoma excision and core biopsy specimens. Histopathology 2009, 54(2):248-253.

33. Ihemelandu CU, Naab TJ, Mezghebe HM, Makambi KH, Siram SM, Leffall LD, DeWitty RL, Frederick WA: Treatment and survival outcome for molecular breast cancer subtypes in black women. Ann Surg 2008, 247(3):463-469.

34. Yang XR, Sherman ME, Rimm DL, Lissowska J, Brinton LA, Peplonska B, Hewitt SM, Anderson WF, Szeszenia-Dabrowska N, Bardin-Mikolajczak A, et al: Differences in risk factors for breast cancer molecular subtypes in a population-based study. Cancer Epidemiol Biomarkers Prev 2007, 16(3):439-443.

35. [http://www.swebcg.se/index.asp?P=NatRikt].

36. Onitilo AA, Engel JM, Greenlee RT, Mukesh BN: Breast Cancer Subtypes Based on ER/PR and Her2 Expression: Comparison of Clinicopathologic Features and Survival. Clin Med Res 2009, 7(1-2):4-13.

37. Heitz F, Harter P, Lueck HJ, Fissler-Eckhoff A, Lorenz-Salehi F, ScheilBertram S, Traut A, Bois AD: Triple-negative and HER2-overexpressing breast cancers exhibit an elevated risk and an earlier occurrence of cerebral metastases. Eur J Cancer 2009.

38. Trivers KF, Lund MJ, Porter PL, Liff JM, Flagg EW, Coates RJ, Eley JW: The epidemiology of triple-negative breast cancer, including race. Cancer Causes Control 2009.

39. Thike AA, lqbal J, Cheok PY, Chong AP, Tse GM, Tan B, Tan P, Wong NS, Tan PH: Triple Negative Breast Cancer: Outcome Correlation With Immunohistochemical Detection of Basal Markers. Am I Surg Pathol .

40. Rakha EA, Elsheikh SE, Aleskandarany MA, Habashi HO, Green AR, Powe DG, El-Sayed ME, Benhasouna A, Brunet JS, Akslen LA et al: Triple-negative breast cancer: distinguishing between basal and nonbasal subtypes. Clin Cancer Res 2009, 15(7):2302-2310.

\section{Pre-publication history}

The pre-publication history for this paper can be accessed here: http://www.biomedcentral.com/1471-2407/10/653/prepub

\section{doi:10.1186/1471-2407-10-653}

Cite this article as: Zhou et al:: Long-term survival of women with basal-like ductal carcinoma in situ of the breast: a population-based cohort study. BMC Cancer 2010 10:653.

\section{Submit your next manuscript to BioMed Central and take full advantage of:}

- Convenient online submission

- Thorough peer review

- No space constraints or color figure charges

- Immediate publication on acceptance

- Inclusion in PubMed, CAS, Scopus and Google Scholar

- Research which is freely available for redistribution

Submit your manuscript at www.biomedcentral.com/submit
Biomed Central 